\title{
A Rare Complication of Insulin Therapy in a Child with Newly Diagnosed Type 1 Diabetes: Insulin Edema
}

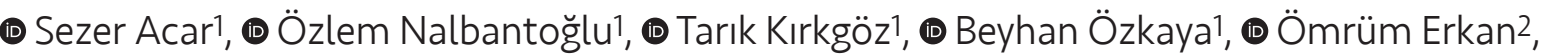 \\ (1) Behzat Özkan1 \\ 'University of Health Sciences Turkey, Dr. Behçet Uz Children's Training and Research Hospital, Clinic of Pediatric Endocrinology, İzmir, Turkey \\ 2University of Health Sciences Turkey, Dr. Behçet Uz Children's Training and Research Hospital, Clinic of Pediatrics, İzmir, Turkey
}

\begin{abstract}
Although insulin therapy has a critical role in the management of patients with type 1 diabetes, it may cause various side effects at varying rates. Insulin edema is a very rare complication that is mostly associated with the initiation of insulin therapy in patients with newly diagnosed diabetes or the intensification of insulin therapy in those with poor glycemic control. Its clinical spectrum ranges from mild peripheral edema to severe serosal effusions (peritoneal, pleural and pericardial) and heart failure. Although it has been known about for a long time, only a small number of cases have been reported on so far and its incidence is not clear. Additionally, most cases are thought to be undiagnosed due to its mild clinical presentation. Here, we present a 10 -year-old male with type 1 diabetes who developed insulin edema following insulin therapy and improved spontaneously with fluid/salt restriction. In conclusion, it should be kept in mind that there is a possibility of the development of insulin edema after the initiation of insulin therapy in patients with diabetes.
\end{abstract}

Keywords: Edema, insulin, type 1 diabetes, ketoacidosis

\section{Introduction}

Insulin therapy has a very important role in the management of insulin deficiency. During insulin therapy, various side effects may occur in the short or long term. The most common of these is hypoglycemia and it is known that this can lead to life-threatening consequences. Apart from this well-known side effect, insulin therapy may lead to a rare complication characterized by partial or generalized edema without liver, kidney or heart involvement (1). Although this clinical entity has been known about since the 1920s, it has only been reported on for a small number of cases to date (2). It has been described as a condition which may occur following the initiation or intensification of insulin treatment in children and adolescents with newly diagnosed type 1 diabetes and in adults with poorly controlled type 2 diabetes $(3,4)$. The clinical presentation of insulin edema can range from mild peripheral edema (mostly) to heart failure/serosal edema (very rarely) $(4,5)$. Although various mechanisms thought to cause edema have been proposed, the pathophysiological basis underlying insulin-associated edema has not yet been elucidated (3-5). This condition is transient and often resolves spontaneously without treatment. Here, we present a 10 -year-old male with type 1 diabetes who developed insulin edema following insulin therapy and improved spontaneously with fluid/salt restriction.

\section{Address for Correspondence}

Sezer Acar, University of Health Sciences Turkey, Dr. Behçet Uz Children's Training and Research Hospital, Clinic of Pediatric Endocrinology, izmir, Turkey Phone: +90 02324116000 E-mail:dr.acarsezer@gmail.com ORCID: orcid.org/0000-0002-0768-835X

Received: 23.02.2021 Accepted: 15.03 .2021

${ }^{(0)}$ Copyright 2021 by Ege University Faculty of Medicine, Department of Pediatrics and Ege Children's Foundation The Journal of Pediatric Research, published by Galenos Publishing House. 


\section{Case Report}

A 10-year-old male with complaints of weakness, polyuria, polydipsia, and polyphagia for a month, rapid breathing for a week and weight loss ( $5 \mathrm{~kg}$ over 3 months) was admitted to the emergency service. He was born via spontaneous vaginal delivery at term with weight of 3,880 grams. No consanguinity between parents or history of diabetes in his relatives was noted. On physical examination, his weight was $23.9 \mathrm{~kg}$ [-0.9 standard deviation score (SDS)], his height was $129 \mathrm{~cm}$ (-0.8 SDS), his calculated body mass index (BMI) was 15.02 (-0.7 SDS), his respiratory rate was $43 /$ minute, his body temperature was 36.2 degrees, his blood pressure was $106 / 72 \mathrm{mmHg}$, and his skin and mucous membranes were dry. He showed Kussmaul's respiration. In laboratory studies, glucose was $473 \mathrm{mg} / \mathrm{dL}$ (60-100), sodium was $132 \mathrm{mmol} / \mathrm{L}$ (137-145), potassium was $3.4 \mathrm{mmol} / \mathrm{L}$ (3.5-5.5), chloride was $107 \mathrm{mmol} / \mathrm{L}$, urea was $6.6 \mathrm{mg} / \mathrm{dL}$, creatinine was $0.9 \mathrm{mg} / \mathrm{dL}$, venous blood $\mathrm{pH}$ was 6.96 and $\mathrm{HCO}_{3}$ was $6.0 \mathrm{mmol} / \mathrm{L}$ (22-26), $\mathrm{PCO}_{2}$ was $22.9 \mathrm{mmHg}$ (3545), glycosylated hemoglobin A1c (HbA1c) was $12.9 \%$, and insulin was $0.8 \mathrm{mU} / \mathrm{L}$ ( $\mathrm{N}: 2-13)$. Urine analysis revealed ketonuria and glucosuria. Further laboratory investigations revealed positive anti-islet cell and anti-glutamic acid decarboxylase antibodies. Diabetic ketoacidosis was considered and infusions of $0.1 \mathrm{unit} / \mathrm{kg} /$ hour intravenous regular insulin and $3,000 \mathrm{cc} / \mathrm{m}^{2}$ fluid (consisting of 128 $\mathrm{mmol} / \mathrm{L}$ sodium, $40 \mathrm{mEq} / \mathrm{L}$ potassium and $5 \%$ dextrose) were initiated. At the $26^{\text {th }}$ hour of follow-up, as the clinic of ketoacidosis improved, fluid therapy was stopped (a total of 2,890 mL of fluid was given) and intravenous insulin treatment was shifted to subcutaneous regular insulin (1 unit $/ \mathrm{kg} /$ day). Regular insulin therapy was given for two days, treatment was switched to a combination of glargine and aspart. On the $3^{\text {rd }}$ day of the follow-up, non-tender, pitting edema without skin discoloration developed over the ankles. On the sixth day of his follow-up, his edema extended to the tibiae, periorbital region, scrotum and penis (Figure 1). He did not have respiratory complaints and his other system examinations were normal. His body weight increased to $27.6 \mathrm{~kg}$, blood pressure was $98 / 56$ $\mathrm{mmHg}$, serum sodium was $134 \mathrm{mmol} / \mathrm{L}$, potassium was $3.6 \mathrm{mmol} / \mathrm{L}$, urea was $8.9 \mathrm{mg} / \mathrm{dL}$, creatinine was $0.5 \mathrm{mg} /$ $\mathrm{dL}$, albumin was $3.2 \mathrm{~g} / \mathrm{dL}$ (decreased from $3.9 \mathrm{gr} / \mathrm{dL}$ ), blood $\mathrm{pH}$ was 7.43, $\mathrm{HCO}_{3}$ was $25.4 \mathrm{mmol} / \mathrm{L}$, and albuminuria/ proteinuria was not detected. Echocardiography, abdominal ultrasonography and chest radiography of the patient were normal. Urine output was $1.4 \mathrm{cc} / \mathrm{kg} /$ hour. In this patient whose glucose levels were being regulated with intensive treatment, insulin-associated edema was considered and

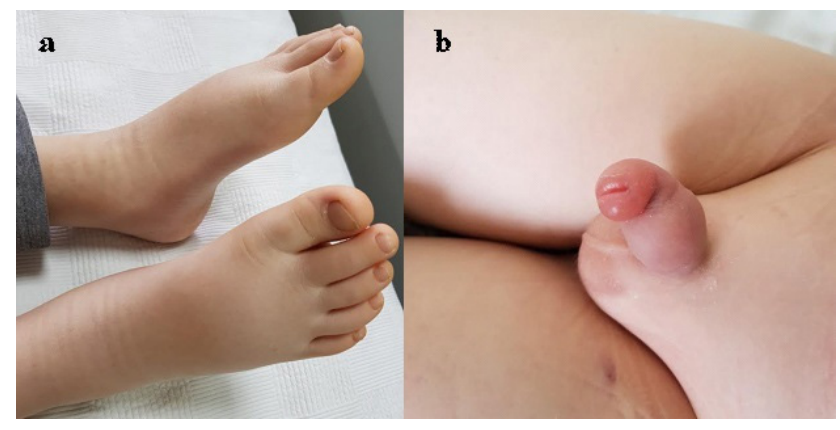

Figure 1. Swelling of the lower extremity (a), scrotum (b), and penis (including the prepuce) (b) on the sixth day of follow-up

he was treated conservatively with fluid and salt restriction. The daily total insulin dose was adjusted according to glucose levels and gradually decreased to $0.5 \mathrm{IU} / \mathrm{kg} /$ day. When the patient's glucose regulation was achieved and an improvement was observed in the edema, he was discharged. In outpatient follow-ups, it was observed that the edema completely resolved 12 days after the beginning (weight decreased to $25.9 \mathrm{~kg}$, albumin $4.2 \mathrm{gr} / \mathrm{dL}$ ).

\section{Discussion}

We present a mild form of insulin edema that occurs after the initiation of insulin treatment and did not cause systemic deterioration in a 10 -year-old patient with newly diagnosed type 1 diabetes mellitus. Although this complication has been known about for nearly a century, it has rarely been reported or sometimes may not be recognized (1-3). The diagnosis of this disease, whose incidence is unknown, is based on the exclusion of all other causes (cardiac, renal, etc.) that may lead to edema. Its clinical severity can range from severe serosal effusions and heart failure to mild peripheral edema. Almost all of the cases in which insulin edema was reported in childhood have been newly diagnosed with type 1 diabetes as in our case (1-8). The clinical course of this disease, which is often transient and benign, is self-limited and mostly resolves spontaneously in children or adolescents (4-8). However, it may present with severe clinical manifestations such as pleural effusion and heart failure in elderly patients with pre-existing cardiac diseases (9).

Although the pathophysiology of this disease has not yet been clarified, various mechanisms have been proposed. Leifer (2) suggested that excessive fluid retention in tissues secondary to glycogen accumulation was responsible for the pathophysiology of insulin edema. In the following years, the anti-natriuretic effect of insulin on the diluting segment of distal nephrons was recognized and it has been suggested that it may lead to this clinical picture by altering electrolyte 
transport $(4,10)$. Moreover, it was emphasized that insulin can enhance renal sodium absorption (anti-diuretic effect) by stimulating $\mathrm{Na}+/ \mathrm{K}+$-ATPase in the proximal tubule and also by increasing expression of $\mathrm{Na}+/ \mathrm{H}+$ exchanger 3 and thus contributes to the development of this clinical condition (4). Another proposed mechanism to explain fluid retention is inappropriate hyperaldosteronism (11). However, patients with normal serum aldosterone levels have also been reported (7). Apart from these suggested mechanisms, chronic hyperglycemia in these patients has been associated with increased capillary permeability, which leads to the passage of albumin, the major protein constituent of the intravascular space, to interstitial tissues (transcapillary escape of albumin) and an increase of oncotic pressure in the tissues and thus, results in edema $(1,4,12)$. In addition, it is thought that in the catabolic process with insulin deficiency, intensive fluid replacement may cause fluid extravasation to the third space and worsen the clinical picture of edema, which is thought to be similar to the pathophysiology of refeeding edema that occurs after fluid resuscitation in severe malnutrition anorexia nervosa cases (1). The low serum albumin level detected in our case on the day the edema deteriorated suggests the mechanism of transcapillary albumin loss. However, cases without a decrease in serum albumin levels have been reported (4). Having said this, we could not measure serum aldosterone level as seen in most other cases presented. In addition, while female gender and being underweight were predominant in childhood and adolescent cases with insulin edema reported in the literature, our case was male and had normal weight and BMI despite weight loss $(4,8)$.

Insulin edema is a different entity from insulin allergy. Insulin allergy has been reported with a frequency ranging from $0.1 \%$ to $3.0 \%$ of patients who received insulin therapy (13). IgE-mediated (type 1) reaction is by far the most common type. However, although rare, type 2 or type 4 type reactions have also been reported (13). Clinical findings may occur immediately (type 1) or 2-12 hours after injection (type 3 and 4). In addition, different clinical presentations occur at the injection site depending on the type of reaction. While immediate, erythematous papular, rash and itching are typical findings in type 1, subcutaneous nodules occurring at the injection site, which are formed by different immune mechanisms, are seen in type 3 or type 4 . Type 1 is rarely systemic with urticaria, angioedema, or anaphylactic shock (13). On physical examination of our case, however, no clinical condition suggesting allergic reactions was detected and therefore, insulin allergy was ruled out.
Fluid and salt restriction constitute the main treatment approach of insulin edema $(1,3,4)$. This disease has a mild course in most of cases and completely resolves within 1-3 weeks, as in our case, without the need for additional treatment $(3,8)$. In severe decompensated cases (heart failure, serosal effusions), pharmacological treatment may be required (1). Elderly patients with pre-existing renal, hepatic or cardiac disease are at higher risk in this respect. Considering the suggested pathophysiological mechanisms, spironolactone treatment is one of the drugs that can be preferred in cases with inappropriate hyperaldosteronism. In addition, other diuretics are equally effective and safe $(1,8)$.

In conclusion, it should be kept in mind that there is a possibility of the development of insulin edema after the initiation or intensification of insulin therapy in patients with newly diagnosed or previously known diabetes. Although insulin edema usually has a mild clinical condition and can completely resolve spontaneously within a few days or a few weeks, it should be kept in mind that it may lead to severe systemic decompensation such as heart failure and/ or serosal effusions in patients with pre-existing heart or renal disease.

\section{Ethics}

Informed Consent: Permission was obtained from patients to share their medical information.

Peer-review: Externally peer-reviewed.

\section{Authorship Contributions}

Surgical and Medical Practices: S.A., Ö.E., Ö.N., Design: S.A., B.Ö., Ö.E., Literature Search: Ö.N., T.K., Bey.Ö., Writing: S.A., B.Ö.

Conflict of Interest: No conflict of interest was declared by the authors.

Financial Disclosure: The authors declared that this study received no financial support.

\section{References}

1. Aravamudhan A, Gardner C, Smith C, Senniappan S. Insulin oedema in a child with newly diagnosed diabetes mellitus. Eur ) Pediatr 2014; 173:685-7.

2. Leifer A. A case of insulin oedema. JAMA 1928; 90:610-1.

3. Chelliah A, Burge MR. Insulin edema in the twenty-first century: review of the existing literature. J Investig Med 2004; 52:104-8.

4. Baş VN, Çetinkaya S, Ağladıoğlu SY, et al. Insulin oedema in newly diagnosed type 1 diabetes mellitus. I Clin Res Pediatr Endocrinol 2010; 2:46-8.

5. Mamoulakis D, Bitsori M, Galanakis E, Raissaki M, Kalmanti M. Insulin-induced oedema in children and adolescents. I Paediatr Child Health 2006; 42:655-7. 
6. Greco D. Severe weight gain and generalized insulin edema after the starting of an insulin pump. Can J Diabetes 2015; 39:21-3.

7. Lee P, Kinsella J, Borkman M, Carter J. Bilateral pleural effusions, ascites, and facial and peripheral oedema in a 19-year-old woman 2 weeks following commencement of insulin lispro and detemir--an unusual presentation of insulin oedema. Diabet Med 2007; 24:1282-5.

8. Derya Bulus A, Andiran N, Osman Köksal A. Insulin edema in type 1 diabetes mellitus: report of a case and brief review of the literature. Iran I Pediatr 2016; 26:e5077. doi: 10.5812/ijp.5077

9. Sheehan JP, Sisam DA, Schumacher OP. Insulin-induced cardiac failure. Am J Med 1985; 79:147-8.
10. DeFronzo RA, Cooke CR, Andres R, Faloona GR, Davis P). The effect of insulin on renal handling of sodium, potassium, calcium, and phosphate in man. J Clin Invest 1975; 55:845-55.

11. Kalambokis G, Tsatsoulis A, Economou G, Tsianos EV. A case of insulin edema with inappropriate hyperaldosteronism. I Endocrinol Invest 2004; 27:957-60.

12. O'Hare JA, Ferriss JB, Twomey B, O'Sullivan DJ. Poor metabolic control, hypertension and microangiopathy independently increase the transcapillary escape rate of albumin in diabetes. Diabetologia 1983; 25:260-3.

13. Haastrup MB, Henriksen JE, Mortz CG, Bindslev-Jensen C. Insulin allergy can be successfully managed by a systematic approach. Clin Transl Allergy 2018; 8:35. 